\title{
Explanation or Understanding? Movement Studies Between Natural Sciences and Cultural Studies
}

Authors' contribution:

A) conception and design of the study

B) acquisition of data

C) analysis and interpretation of data

D) manuscript preparation

E) obtaining funding

\section{Henning Eichberg}

University of Southern Denmark, Denmark

\section{KEYWORDS}

\begin{abstract}
Movement studies are - like health studies - placed between natural sciences and cultural studies as well as between quantitative and qualitative methods. That is why they are challenged by some methodological contradictions. Yet the dual relations between nature and culture, and between quantitative and qualitative methods, may be of superficial character.

Deeper beneath, one finds tensions with theoretical implications: between the quest for evidence and the comparative method, between generalization and case study, between explanation and understanding, between the correctness of the answer and the quality of the question, between affirmative and fluent knowledge, between factors and connections, between data and patterns, between the state of research and historical change of knowledge, between objectivity and subjectivity, and between theory and philosophy. There seems to be something akin to cultural struggle in the field of knowledge.

Yet the dual contradictions do not comprise two neatly separated "cultures of knowledge" that exclude each other. There are cross-disciplinary connections and overlaps, which help toward an understanding of human life.

movement studies, theory of science, phenomenology, epistemology, tacit knowledge, cultural struggle
\end{abstract}

\section{The situation and the problem: Movements studies between the chairs}

Human beings move - in dance, play and game, sport, gymnastics, military exercise, outdoor activities, fitness training, physiotherapy, chiropractic, ergotherapy, everyday movement in towns, etc. As a theoretical framework embracing this diversity, movement studies have developed in the last two decades in several Nordic countries (Bevagelsesstudier, 2002-2010; Moving bodies, 2002-2008; Movements, $2007 \mathrm{ff}$; University of Southern Denmark Studies in Sport and Movement, 2012 ff). At the origin of this discipline, one mainly finds sport studies, as these constitute already firmly established academic fields. But they seemed to be too narrow to comprehensively analyze the broad range of human being in movement.

The most ambitious definition of movement studies took its starting point from the multidimensionality of the word "movement" in most (or all?) European languages. Le movement, movimento, 
bebcegelse, rörelse, Bewegung, etc., not only designate bodily movement, but also emotional movement ("I am moved") and social movements. These three layers of "movement" - bodily, psychic, and social express a deep wisdom of languages. Thus far, however, research has not taken their connection seriously and have by means of academic isolation either treated single bodily activities as such, or the psychology of emotion as a bodiless state of mind, or social movements as organizations, which were bodiless and free from emotions. In this respect, comprehensive movement studies are a challenge.

Like their forerunners in sport studies, movement studies thus have their place amidst an interdisciplinary cross-field where traditions of knowledge of very different character meet. More than others, a deeper gap leads to the fact that natural sciences and cultural studies "do not understand each other." Normally, these disciplines live their separate lives in separate institutes and separate faculties. In institutes of movement studies, however, biologists may sit door-by-door with historians and sociologists. Yet in very few cases will they even join in interdisciplinary courses to teach the students the different, though connected, aspects of human movement.

Problems of this meeting appear on a down-to-earth level when students are trying to formulate their problem for studying for exams. Should they pose it in the form of a hypothetical statement - or as a question? This sounds like a purely grammatical matter, but upon closer examination, it is more than this.

The hypothesis is usual in natural science. It is expressed as a statement which often has an explanatory character: If factor A - then phenomenon B. (Full stop). This hypothetical, provisional statement can be tested, and the result will affirm or falsify the thesis. In contrast, the formulating a problem in the form of a question has its tradition in humanist studies. It asks from out a given phenomenon into an open space and expresses wonder about the larger connections of this phenomenon: How is the phenomenon A connected with other dimensions of human life - socially, historically, psychologically? (Question mark). Or: If one compares phenomenon A with phenomenon B, what is the difference? (Question mark). Problem questions of this type cannot be "tested", and the result will rarely be a falsification of certain causality. But different connections have to be discussed in relation to each other and contribute to deeper understanding.

In the simple academic practice of problem formulation - through the medium of either a statement or a question - we thus meet deeper contradictions. These are the contradictions between causality and understanding, between falsification and wondering, between closing and opening of knowledge.

The following reflections start by a more systematical questioning of these and related contradictions, which reflect different theoretical traditions of knowledge. From this discussion of theory, the further question arises of whether these different approaches of knowledge really make up two neatly separate cultures of knowledge. Alternatively, do we find relevant areas of contact and overlap or even something third? From there, we turn to phenomenology as a possible method, as a way of bridging the gap. However, the question arises, which type of phenomenology do we talk about? We meet different phenomenological approaches, and this is what can be applied to the fields of both health studies and movement studies. From here, we can turn to the question whether and how we do - or should do - theory or philosophy.

\section{Theory: Dual tensions in the world of research}

There is a long tradition of placing the questions about the two differing scientific traditions into the established dualistic pattern of

- natural sciences versus humanist studies.

This is often identified with the dualism of

- quantitative method versus qualitative method.

These dualisms remain, however, at the surface. Beneath this surface, we find deeper contradictions and tensions such as: 
- quest for evidence versus comparison,

- generalization versus case study,

- explanation versus understanding,

- correctness of the answer versus quality of the question,

- factors versus connections,

- state of research versus history of knowledge,

- objective versus subjective research,

- theory versus philosophy.

\subsection{Evidence versus comparison - definition versus comparison}

The quest of evidence in connection with methods of randomization has spread far among the sciences. A test group shall be confronted with a control group. This method is derived from certain biological ways of reducing a problem to a test that can be implemented in a laboratory. A test group A is tested with a certain method of treatment in the laboratory, while a control group B remains outside without this particular treatment - and the results of the two groups are compared: Does the treatment work or not? From the natural sciences, demands for evidence have been entering the field of social studies, too. In the political world, contracting authorities tend more and more frequently to demand evidence-based results.

However, in the field of social relations it is extremely difficult or even impossible to implement this reduction. An example is the research in municipal sports policy or municipal health policy. Indeed, one can apply a certain intervention in one municipality in order to measure an outcome, and research can accompany this process. But one cannot find another municipality as a control group where nothing is done at all. There are zero cases. We cannot isolate and treat human beings in their complex social relations as if they were in the laboratory. The "natural experiment" as social intervention follows logic other than the experiment under laboratory conditions.

What research can do, however, is to compare different municipalities (Ibsen, 2009). We can focus on the municipalities A and B and find relevant differences. But this does not produce "evidence" in the narrow sense of established science. It is comparison, developing in an open way questions towards differences and similarities: If we compare municipality $\mathrm{A}$ and municipality $\mathrm{B}$, which differences (or similarities) do we discover?

The priority of comparison in human studies also questions the imperative of definition. In academic mainstream, the student is expected first to define his or her terms before the research is done. Normally this definition work is done by reference to one or other authority that has already delivered a certain definition. This brings an authoritarian undertone to the process, which should not be welcome in intellectual work. How can an authority define a term that the researcher now will apply to quite another context?

Terms do not live their life in an abstract universe (as the Platonic assumption of heavenly ideas would suggest). Terms are words, and words have their etymology, their historical change - and they differ from language to language, always in relation to diverse cultural practices. This is the case for fundamental concepts like "the body", which in some languages is expressed in dual configurations as in German Körper and Leib or in Danish krop and legeme (Eichberg, 2010, chap. 15). It is also true for the dialectics of "play" and "game", likewise in Danish leg and spil, which in some languages only can be expressed by a single word, as by the German Spiel or by the French les jeux (Eichberg, 2012). "Nature" has undergone historical change and can, thus, be understood as "the whole" - as in "natural sciences" - or as "the other", for instance when saying "back to nature" or "out into the green nature" (Eichberg, 2010, chap. 6). "Sport" is related to fairly different activities, some being oriented towards results, some disciplining, and some related to people's meeting, body experience, and togetherness (Tang, 2010). 
Thus, terms used in cultural studies can be compared, but they cannot be "defined" in a strict sense. Definitions would be an attempt to eliminate the cultural, linguistic, and historical relativity of words.

\subsection{Generalization versus case study - reality versus potentiality}

It is mostly in natural sciences that we find demand for representative results. Research should produce results that can be generalized. From this point of view, the study of a single case - as it is usual in cultural studies - may be quite interesting, but it is regarded as "just anecdotal".

Upon closer examination, there is a deeper contradiction beneath this dualism of generalization versus case: between what people actually do - and what they can do.

The demand for generalization has its focus on what people typically do, as it may be proven by statistical significance. This demand dominates the natural sciences, especially in their positivistic part, where it is called "the analytical method". "Analytical" means here, on the basis of the representativeness to produce a result, which can be generalized. One single case is not enough. It is only the representative multitude of cases that make up the whole picture in which statistical overview is the one side and natural law - like the laws of physics - are the other: If A then B.

However, by generalization one cannot conclude what is really happening in the concrete lives of human beings. The single case can differ seriously from the statistical overall picture. A concrete human being, who according to gender, age, social class, rural or urban life, ethnicity, nationality, etc., should behave a certain way, may behave quite differently. And yet this human being does not behave accidentally, but instead has good reasons to behave in just this particular way. These good reasons demand analysis, too.

The case study points in directions other than generalization. One direction is heuristic: The case can be studied for explorative reasons. The study of a single case can open up new questions and new knowledge.

But there is also another need to do case studies: From any single case, one can conclude what a human being is able to do. Philosophically, the case study is thus justified by potentiality rather than by reality (which can be generalized). Even the most extreme case, which is unlikely and not representative at all, is enlightening by telling us: See what we - maybe - can expect in real life. Nazism is an example. Nazi dictatorship was unique in history, lasting just a few years in a single country - among thousands of years of history in hundreds of countries. And yet, it was not "just anecdotal". As a statistically insignificant phenomenon, Nazism attracts immense research - and will do so again and again. What once has happened may happen again - or not?

Upon closer observation, even measurement in natural science style is always confined by certain historical-cultural limits, i.e., it also represents a particular case. Based on representative data about a certain population here and now, one cannot conclude how the data would have been 100 or 300 years ago - or how they will look like in 50 years - or how they would look like in other populations. This case character of measured data is normally not reflected as a limit of representative data.

The difference between generalizing science and case studies can thus be sharpened as confronting research in reality (natural science: what is?) with research in potentiality (humanist studies: what could be?). And yet, a closer glimpse reveals a more complex relation. The potential may be at least as real as the "real". The paradox is that the scientific quest for representative data wants to document reality - what people really do; but by its method - laws, tendencies, and normal data - it produces instead probable and potential results. Humanist studies, in contrast, want to throw light on human potential - what people can - but they present pictures of a reality that is happening here and now or which has happened in the concrete case. 


\subsection{Explanation versus understanding}

Science wants to explain phenomena: Why did that happen - what is the reason? This sounds simple. And yet, the term "explanation" has different meanings and layers, which should not be confused. In common-sense language, explanation means something rather unspecific like deeper knowledge, insight, understanding, and reasonable interpretation. Children conquer the world by their endless questions of the type: Why is the sky blue? Why is the grass green? Why are there men and women? Why... why... why? They want to understand. In this case, explanation and understanding seem to be the same.

In the theory of science, however, explanation and understanding are two different procedures. Explanation is linked to the so-called analytical-empirical method, which is derived from natural science, mainly from physics. It asks for causality: What is causing what? In contrast, understanding is at home in humanist studies of historical, phenomenological, and hermeneutical character. It asks: In which connection to which dimensions can a given phenomenon be understood? (Seiffert, 1969/70; Wright, 1971).

Explanation as search for causal reasons tends to reduce the complexity of connections to certain factors that can be isolated, as in the situation of a laboratory. Among several factors, one or few factors can be given priority. This follows the lineal logic: If factor $\mathrm{A}-$ then phenomenon $\mathrm{B}$.
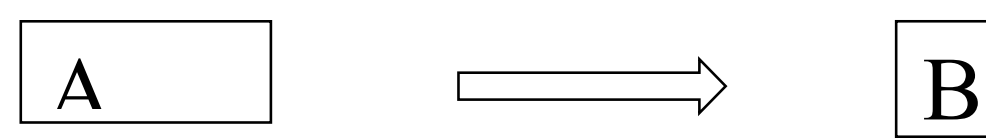

Understanding, in contrast, takes its starting point from a given phenomenon, which is often described by narrative "thick description": a case, a situation, a text, a picture, a biography. From this phenomenon, lines are drawn into different directions. These connections cannot be reduced to factorial "boxes". The number of these directions and connections is in principle endless - that is why any new generations of researchers will discover new aspects.

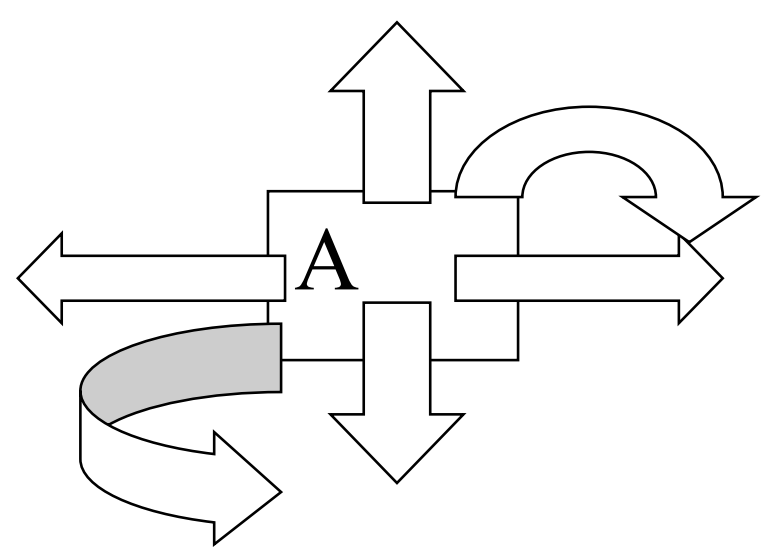

\subsection{Answer versus question - affirmative versus fluent knowledge}

The tension between explanation and understanding is related to the tension between the two modes by which we form a sentence - to statement and question. This leads to the relation between answer and asking. This relation is, however, not a simple one. 
Explanation primarily wants to qualify the researcher's answer. Causal thinking moves in a space of statements that are tested: Either the statement is right or wrong. And the result of an explanation is a statement in the form of an answer, which is thus confirmed - and finished by a full stop.

In contrast, understanding - though not being indifferent to "good answers" - has a much stronger focus on the question. The process of understanding opens up into a larger space and will remain open also after the research process is finished - or it will be even more open than before. Every answer after a process of understanding will open up to new questions.

Astonishingly, there is not much existing research and literature about the strange phenomenon that we call a question. What does the question mark tell us? The question mark is a graphical sign as well as an intellectual symbol and a marker of bodily movement. By its combination of the curved line with the point, it represents a movement of searching and a nearly-and-yet-not-quite symmetry, which is not so different from the labyrinth (Eichberg, 2005).

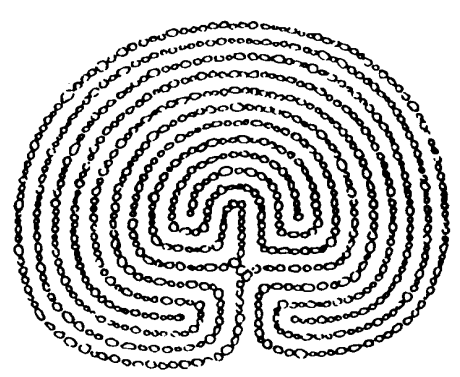

Furthermore, the question is formed by bodily means - the one who asks raises the voice. The raising of the voice can turn the statement "This is true" into something quite different: "This is true?" We can say: "This is healthy" with a tone of certainty - but by a slight change of intonation, it becomes a question: "This is healthy?" What was sure before is by the question transformed into a matter of doubt. The question produces a sort of turning around, a rotary vertigo, and may be in family with laughter on one hand and seduction on the other. The question reveals subversive qualities.

However, there are complex relations between closed and open questions. A provoking psychoanalytic study has launched a polemic against asking as being an obscene form of communication (Bodenheimer, 1984). The study focused on the rhetorical, demagogical, conservative-restorative, and inquisition-like forms of the question. But this cannot be the last word. The question is also opening up, wondering, producing new insights, even subversive.

Anyway, the one-sided focus of positivism on the correctness of the answer is not satisfying. Logical Positivism was built upon the existence of "fundamental statements" and "data" (German Sachverhalte and Basissätze), which can be verified or falsified. These statements make up the basis of constructing theoretical models on an abstract level above them. The world of science consists of fundamental data that can be evaluated by either "yes" or "no". There is no third way between meaning and nonsense (Wittgenstein, 1921; Geier, 1992, 106-124). Critical Rationalism has modified this by pointing towards the imbalance between verification and falsification and only left falsification as a legitimate way of treating data (Popper, 1969, 104-108). The common denominator of positivistic approaches is that science and epistemology are based on statements - not on questions.

The one-sided orientation of positivism towards the statement or hypothesis has its background in the striving towards the right-versus-wrong test. A statement can be wrong - but can we ask wrong questions? In some way we can indeed, as in the example of: "Have you finally stopped hitting your wife?" This question includes an assumption, and this may be wrong. And yet, more basically it is difficult to classify questions after the criterion of right or wrong. Questions may be more or less appropriate. 
The imbalance between statement and question leads us back to the simple matter of academic problem formulation that was initially identified. If research starts with a hypothesis, it starts by a hypothetical, provisional - answer or statement: If A - then B. The way of research will be a test. Something shall be proven. The result of the test will be a verification or falsification of the hypothesis: right or wrong.
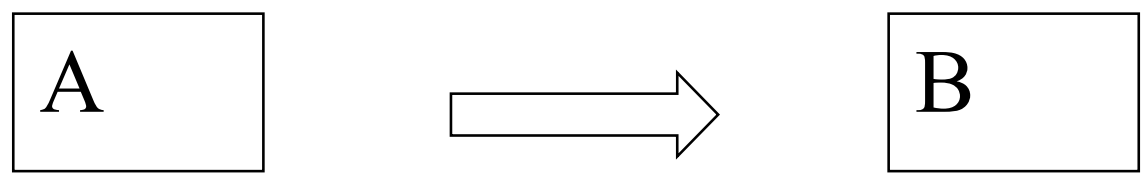

\section{full stop}

Alternatively, however, one can choose the problem formulation in form of a question: If we compare $\mathrm{A}$ and $\mathrm{B}$ - for instance, sport in $\mathrm{X}$ and sport in $\mathrm{Y}$, or: movement culture of males and of females, or: motion of young people and motion of elderly people - what will come forward? The focus is more on connections than on correctness. A test is not possible, and nothing shall finally be proven. But additional questions will arise.
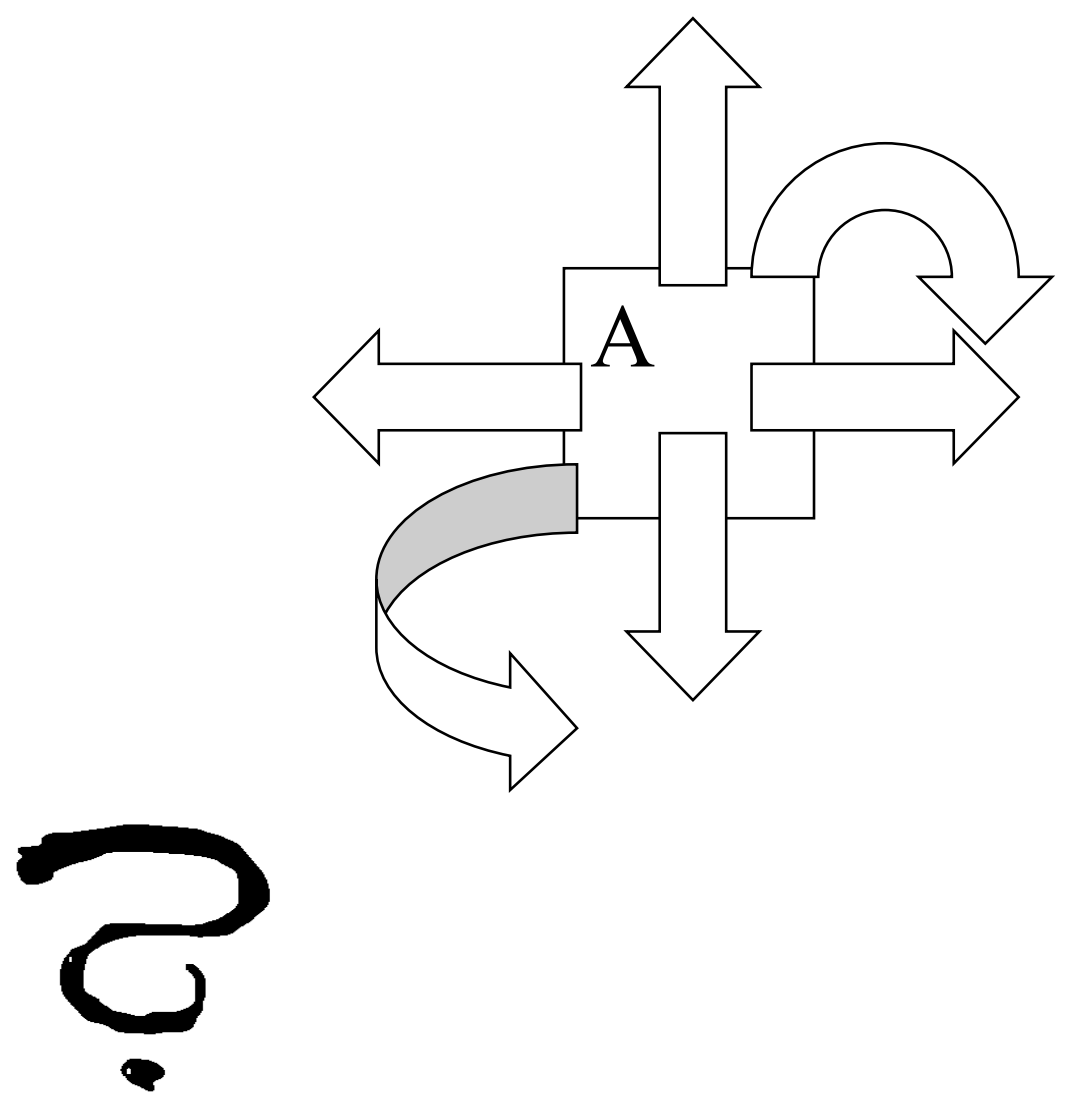

In other words, after positivist research, which has departed from a hypothesis, the initial statement is affirmed or rejected, and the matter can be "closed". After research, which has started by a question, knowledge has widened and deepened, but there has arisen more qualified questions than before. 
This - unbalanced - tension between answer and question points towards different strivings for knowledge - strivings of both intellectual and cultural-bodily character. On the one hand, knowledge strives towards closed knowledge, which is manifest in the "result". We want to be sure, making our knowledge firm - and choose the way of affirmation. Literally, the statement "stands". On the other hand, research strives towards opening up, making flowing and fluent. It reflects the unsure side of research, the importance of doubt. Questions make the world dance. Knowledge as a "state" versus knowledge as a "flow" - statement versus dance - this is more than just a game of metaphors.

And yet, the two directions of closing and opening, of answer and question, of result and subversion, are not in a dual balance - and they do not at all constitute an either-or. A popular says that there is no wise answer without a wise question. There is interplay between question mark and full stop, and the one may depend on the other.

\subsection{Factor versus connection - data versus pattern}

When searching for affirmative knowledge, one typically talks about "factors". This is often done in a naive way, which has entered strongly the social sciences and humanities. But what is a factor?

The term "factor" has an undertone of mathematical or physical objectiveness and abstractness. This also has its fascination in cultural studies.

A factor is a single element that can be defined and measured. Factor is a "factum", a fact. It is like a little box. Or critically said: "Factor" is a form of reification.

This objective box is part of the process of doing, of effecting. "Factor" is derived from Latin facere, to make something. A factor "makes" something, it effects something, it acts. Data, variables, determinants are factors suitable for describing input/output relations. Factors are associated with causal thinking.

More concretely, the factor is associated with human action and its driving forces. These may be seen from inside - motivations, or it may be - seen from outside - interventions. The "making" of a factor often means: what human beings want to do themselves or what they could be motivated to do by administrative, pedagogical or political action. Factors often have an undertone of intervention - intervening into other human beings' lives: Your life and practice can be changed! This makes factor thinking attractive for administrators and sponsors of research. Factors can be handled in a normative, political context, teaching us what is to be done.

Outside the world of physics and chemistry, the scientific quest for factors has resulted in a plurality of factors having to be considered. That is why one talks about multi-factorial relations, which are typically constructed into the form of models. An example of factor models is the Theory of Planned Behavior. It strives to describe behavioral change, going from determining factors to physical activity.

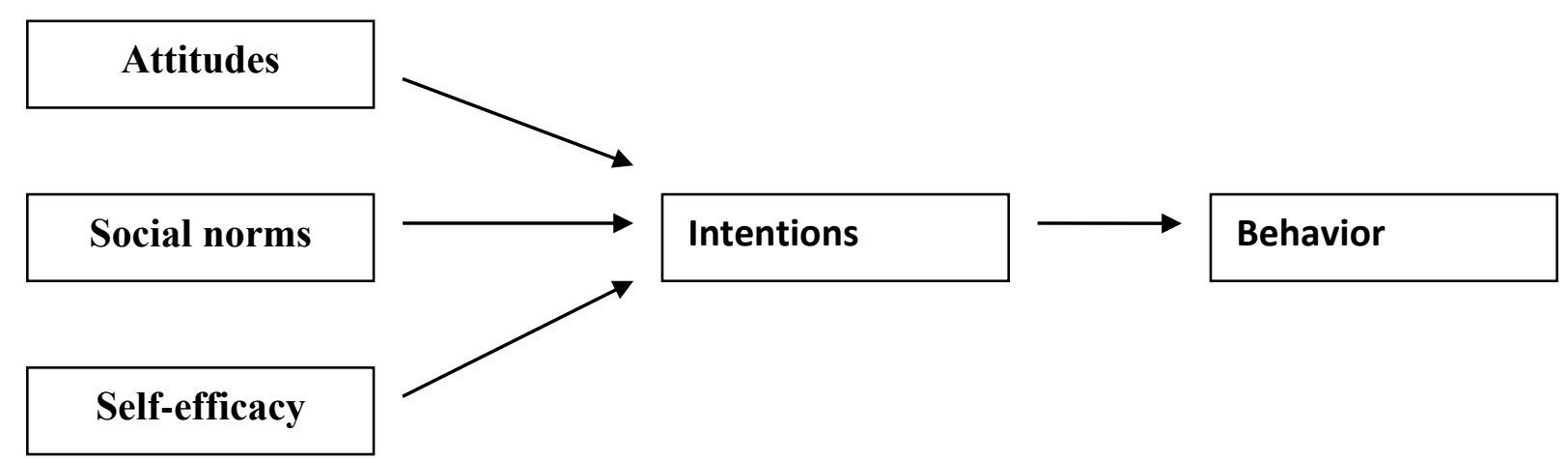


The boxes suggest that individual self-efficacy and attitudes are independent of social norms. The model remains silent about social and cultural relations that are not "norms".

Another example of ongoing factor research in social sciences is the project Policy Factors Leading to International Sporting Success (Andersen/Ronglan, 2012, 23-24). One main focus of SPLISS is investment, as financial means invested in sports can be measured. Another important cluster of factors is institutional: Institutions favoring sport success can be organized. It is more difficult to measure, but one can try.

Side by side with investment and organization, however, one has also discovered social-cultural "factors" - and what is this? During decades of research, sociologists have documented and discussed religion as influencing sport success on the Olympic level. A typical result from statistical sociology was that the Protestant religion in a given country would correlate with high sport success measured in Olympic medals whilst the Catholic religion would diminish Olympic chances (Lüschen, 1962; Seppänen, 1972). The Baltic states in the years between the two world wars have been illustrative: Protestant Estonia had great Olympic success in contrast to Catholic Lithuania, with religiously mixed Latvia in-between. Christian Orthodoxy as well as Buddhism had negative correlations with Olympic ranking, while Communism had positive effects. Was or is Communism a religion?

Anyways, it was suggested that religion is a factor. If factor is something that can be measured and changed, however, doubt may arise. Should or could the religion of Italy be changed to Protestantism (or Communism) in order to raise the level of Olympic productivity? And do recent successes of Chinese athletes mean that the factor "Buddhism, Taoism, and Confucianism" has been replaced by the factor Communism?

Given the excellent successes of Black - African and Afro-American - runners, one has also begun to discuss "race" as a factor (John Bale in Brownell, 2008, 339-340). This shows some highly problematical implications of factor reification, both methodologically and politically.

Side-by-side with religion and "race", gender is sometimes defined as a factor. Indeed, there is often a gender bias in cultural phenomena - for instance, girls preferring horse riding while boys preferring football. However, one can doubt whether this means that gender is a "factor", being measurable and doing something. It is not their manhood that makes boys play football or their womanhood that makes girls ride. The gender unbalance is a connection and relation rather than a "factor".

Factor thinking plays an important role in health sciences, where it was imported from positivistic biology. The factor became a part of the apparatus-mistake model and is handled as a sort of thing, a sort of reification, connected with causality. Also, it has here an undertone of normativity. This is expressed by the term of the so-called risk factors, which threaten healthy life. Danish welfare discourse sums risk factors up by the formula KRAM, an abbreviation for kost (meal), rygning (smoking), alcohol, and motion. These four factors - unhealthy meals, smoking, alcohol, and lack of motion - are what people should avoid.

However, there are some paradoxes inherent in this factor thinking. Swimming is a risk factor for drowning. If drowning should be avoided, people should not swim - should they? And: Eating is a risk factor for overweight and obesity. If these dangers should be avoided - should people drop the factor eating? And sharpened in an absurd way: Life is a risk factor for illness and death. Should we therefore abolish the risk factor life?

Health is connected with emotions, social relations, and movement. That is why the term "connection" can replace the term "factor". When talking about connections instead of factors, one does the step from "little boxes" to relations. There relations are, surely, difficult or impossible to measure, but they have meaning for human beings and their physical lives. It is the step from data to patterns, to configurations of human practice.

The term "human factor" is illustrative for this problem. In some studies, after having defined and measured different factors like gender, social class etc., on will find some individual variances, which are 
called "the human factor". This expresses the insight that none of the abstract (non-human?) factors is sufficient to explain the given phenomenon - that is why "the human factor" is introduced as a joker.

The contradictory relation between factors and connections has more than just theoretical significance. There are - sorry to say - not just a few examples from the practice of academic writing: When students write about what they understand as humanist dimensions and apply factor thinking, the study of culture typically goes missing. Write "factor" - and "culture" will vanish. This can, with some irony, be called the law of the factorial disappearance of culture.

\subsection{State of research versus historical change of knowledge}

A further dualism is revealed in relation to the history of knowledge. Natural sciences focus primarily on the so-called state of research - and positivistic approaches do the same in the social sciences. This state of research is regarded as the well-defined basis from which any future gain of research can be achieved.

However, natural sciences have a history, i.e., their ways of thinking and observing, their concepts, and their methods have changed through time and in connection with society and culture (Teich/Porter/Gustafsson, 1997). Instead of a state of research, there is a dynamic of change. This historical change is more than just an accumulation of "confirmed knowledge" through the years. From time to time, there may occur fundamental shifts of paradigm in the history of science, as Thomas S. Kuhn (1962) showed in his famous studies on the scientific revolutions of physics and astronomy.

This historical change makes any state of research, as it pertains here and now, fundamentally relative. It may be different tomorrow, as it has been different in past times. Again, knowledge balances between the firm and the flowing.

\subsection{Objectivity versus subjectivity}

The antagonism between firm knowledge and flowing knowledge is also related to another dualism, which is linked to the relation between object and subject. The mainstream of natural sciences and of social studies sees as its object something neatly separated from researcher subjectivity. Here is me, the researcher, and there is my object. And the discourse about my object should be thus, that it can be reproduced by anybody else - it should be objective. In medical science, this concept of object can be derived from the dead body, the corpse, which was dissected in order to produce knowledge. As soon as the object is a living being, the separation between object and subject becomes problematic.

The dead-body-objectivity also affects researchers themselves. Generations of scientists and philosophers have, for instance, demanded the researcher refrain from emotions, which were just disturbing the process of objective enquiry (McNamee, 2008). The scientist or philosopher should obtain a virtual state of apparent death (in German: Scheintod) in order to avoid unfitting subjectivity (Sloterdijk, 2010). The subjectivity of the researcher should be made invisible - by elaborated techniques of "blinding".

This attitude inhibited, however, a self-critical analysis of the scientist's work. The ethnopsychoanalyst George Devereux (1967) demonstrated the degree to which the anxiety of the researcher contributed to constructing the primacy of method in behavioral sciences. Peter Sloterdijk (2010) showed how intellectual exercise influences the process of knowledge - and is trained for this purpose. And not at least: The researcher has and is also a body himself. This can be "blinded", but blinding will not make the body of the observer disappear.

Objectivity and subjectivity are thus much more interwoven than naïve analytical thinking would have thought. And as a third, furthermore, the inter-subjective dimension is revealed as soon as the relation between I, It and You is regarded. (About this and the Buberian approach see below.) 


\subsection{Theory versus philosophy}

In light of these dualisms, an important difference between theory and philosophy is revealed. What they have in common is that they try to present a coherent framework of knowledge, yet they are not identical.

Theory is normally understood as an abstraction that is related to certain empirical data and tends to deliver the framework for correct answers. A theory is often - though not always - understood as something that can be tested. Theory has a character of closing: This is how it is!

Philosophy, in contrast, cannot be tested. It focuses primarily on questions. Philosophy opens up: How is it? Or: What is...?

What makes the picture unclear is that philosophers sometimes have been tempted to deliver answers, too. Having received the personal status of a guru, certain philosophers have tried to explain the world for the unenlightened non-philosophers. Georg Wilhelm Friedrich Hegel presented his system of knowledge, as if the Weltgeist (world spirit) himself had taken place on his lecturing desk in Prussia. Martin Heidegger was so impressed by his own understanding of Sein and Dasein (Being) that he strained to be the philosophical leader of Nazism - the philosophical Führer of the Führer. Jürgen Habermas has explained for a recent generation what German constitutional patriotism is, what Europe is, and what world democracy is. Philosophers are just human beings with ambitious and vain inclinations. However, philosophy is more - and other than - the personal ambition of a pompous master-thinker. Philosophy is a way of questioning.

An example for philosophical method is the question: What is the human body, what is bodily existence? A plausible answer to this has been the differentiation between the bodies we have and the bodies we are. In German language, this is related to the two different words for "the body," Körper and Leib. In French phenomenology, one has analogically constructed the dichotomy between the objective and the subjective corps. And in American "Somatics", one has developed the contradiction between body and soma. All this has sometimes been overemphasized by postulating an existential dualism of either/or - either having a body or being a body. However, where there are two, the question of the third will arise. Indeed, human existence is characterized by reflexivity: The human being is able to change between the two relations (Plessner, 1941). This reflexivity can be understood as a third relation. And there are other - third inter-bodily relations, which can be described as the "interfacial space", the "aura" and the "sonosphere" between human beings (Sloterdijk, 1998: 141-209, 211-268, and 487-531).

The relation between having a body and being a body is connected with the relation between objectivity and subjectivity. Though this contradiction makes up a well-established topos of epistemological reflection, one finds also here a third - the inter-subjective dimension. Martin Buber (1923/1986) challenged the scientific mainstream, which has reduced philosophy towards the I-It relation (corresponding to the objective body we have) and to the I-I relation (corresponding to the subjective body we are), which is, however, less accepted in academic thinking. The third is the I-You relation (Beziehung) as it becomes manifest in meetings between human beings (Begegnung). The meeting of I and You is the basis for the dialogical principle: "Truth begins between two" (Die Wahrheit beginnt zu zweit). The human being is existentially not alone in the world, but between others, with others, and where others also are. The human being is a Between, a With, and an Also.

None of these relations - having body, being body, and the third; objectivity, subjectivity, and intersubjectivity - can, as such, be tested. And yet, they all contribute to a deeper understanding of human bodily existence. Rather than being theories, they are of philosophical character. From the question "What is the body?" they open up towards further philosophical questions: What is the body we have? What is the body we are? And: What is the bodily existence between body and body? 


\section{Two separate cultures of research excluding each other?}

Looking with the eyes of cultural studies at these established theoretical dualisms one may suppose that they are inscribed in a deeper cultural difference. Have two different cultures produced these theories and methods as their superstructures?

Indeed, in the world of research, the one side and the other side of the dual tensions are often respectively connected. Scientists who work quantitatively and search for evidence try to build control groups, to generalize, and to produce representative knowledge. They strive to explain, use factor models, and focus on the correctness of their answers. They formulate hypotheses, focusing on the state of research, and favor theory that can be proven or tested.

On the other hand, humanist and cultural studies instead use qualitative methods and case studies for understanding complex relations. They prefer comparative studies. They focus on the quality of questions and search connections and patterns. They are aware of the historical change and relativity of both the phenomena under observation and of their own knowledge. They are closer linked to philosophy.

\begin{tabular}{ll}
\hline $\begin{array}{l}\text { Natural sciences } \\
\text { quantitative method } \\
\text { quest of evidence } \\
\text { generalization } \\
\text { explanation } \\
\text { correctness of the answer } \\
\text { affirmative knowledge } \\
\text { factors } \\
\text { data } \\
\text { state of research } \\
\text { objectivity } \\
\text { theory }\end{array}$ & $\begin{array}{l}\text { humanist studies } \\
\text { qualitative method } \\
\text { comparative method } \\
\text { case study } \\
\text { understanding } \\
\text { quality of the question } \\
\text { fluent knowledge } \\
\text { connections } \\
\text { patterns } \\
\text { history of knowledge } \\
\text { subjectivity } \\
\text { philosophy }\end{array}$ \\
\hline
\end{tabular}

\subsection{Can we talk about "two cultures"?}

This connection has sometimes been interpreted as if "two cultures" existed side-by-side in modern intellectual life. The two postulated cultures, which were not only different and neatly separated, were also unable to understand each other. An early attempt to confront understanding (Verstehen) with explanation (Erklären) as a broader cultural matter was launched by the German philosopher Wilhelm Dilthey. He opposed the first-person perspective of humanist hermeneutics, Geisteswissenschaften, with the third-person perspective of natural sciences. Following this line, causal explanation was confronted with teleological understanding, and mechanistic explanation with finalistic understanding (Wright, 1971; Seiffert, 1969/70). Seen in light of our arguments above, however, these may not be the most basic criteria of the difference. Nor is the difference just intellectual or just a matter of logical method, but it may be rooted in different cultures of knowledge - but is it?

Indeed, a broader Western debate about this dualistic relation as a cultural conflict arose when Charles P. Snow held a famous lecture in 1959 in Cambridge on the topic "The two cultures". Snow was an English novelist but had studied natural sciences. He had served as Director of English Electric Co. and Secretary in the Ministry of Technology. Thus balancing between the "two cultures", he launched his critique against the "literary intelligentsia", which one-sidedly referred to literary culture and depreciated the cultural value of natural sciences and technology. In 1962 Snow was answered by Frank Raymond Leavis, an English literary 
critique, in another lecture in Cambridge: "Two cultures? The significance of C.P. Snow." Leavis attacked Snow as an "intellectual nullity" who followed a vision of triumphant technology, Americanism, and emptiness of life. There was no natural-scientist equivalent to reading Shakespeare, he stated. So, cultural struggle was set on the agenda.

Though neither of the two lectures emerged as particular intellectual originality or stylistic brilliance, they hit the deeper problem of cross-disciplinary understanding and gave birth to an international intellectual debate (Kreuzer, 1969).

Indeed, if the dualisms discussed above really would concur in one over-all antagonism, we would have insurmountable problems of communication. It would be fundamentally impossible to understand each other between scientists and scholars of cultural studies, though both are working on the analysis of human body and human movement. The "two cultures" would exclude a cross-disciplinary understanding, both standing in a strictly polemical relation. Instead of cultural struggle there would be intellectual war.

\subsection{Crossing the borders}

However, many relevant research practices cross the border between the "two cultures" - and they do so systematically. This crossing shows that the two dualisms do not concur. They do not make up two antagonistic fields in the real world of research, and they do not constitute one over-all cultural dichotomy of either-or.

For instance, one can very well work quantitatively and at the same time comparatively along humanist questions. This is the case when social research compares sports policies in different municipalities (Ibsen, 2009). Pierre Bourdieu and his school delivered classical quantitative studies about people's taste and habitus. Through these studies, the social typology of people was discovered who have a dog or a cat at home; this lead to two social classes or habitus who live "like dogs and cats", one related to private property and economic capital and the other to public services and cultural capital (Héran, 1988).

One can also - the other way round - study biological material through qualitative cases. This was done in primatology. The ethologist Jane Goodall (1989) studied the chimpanzees of the Gombe National Park in Tanganyika (later Tanzania) finding out that she had to - and could - reconstruct the biographies of the animals more or less in the same manner as human biographies are written. Photographic portraits showed that the observed "objects" had faces. Furthermore, by studying the lives of apes in the rainforest she sensationally discovered the existence of dance, rhythmic music, and "theatre", in chimpanzee society, as well as war and cannibalism. To observe and understand this, the biologist had to enter into dialogical contact with the animals, crossing the border between objectivity and subjectivity, between scientific observation and dialogue, between the observed "thing" and its history.

Epidemiology is another field of medical biology that crosses the borders between nature and culture. Epidemiology studies the distribution and patterns of health-events and health-characteristics in given populations. It is the cornerstone method of public health research, and is essential for informing policy decisions and evidence-based medicine. By identifying risk factors for disease, their causes or influences in a given population, and targets for preventive medicine, epidemiology is clearly part of scientific biology. Yet the epidemiological focus on certain "populations" gives this study a socio-cultural status. The word "epidemiology" contains the word "demos", folk or people. This is not accidental under methodological aspects as well. For a defined population, one cannot construct a control group in the sense of laboratory research. The population is outside the laboratory. However, one can compare one population with another and this is not far from the comparative way of humanist studies.

An important cross-disciplinary field of knowledge, which concerns all scientific work in general, is the history of science. All natural sciences have a history, i.e., their ways of thinking and observing, their concepts and methods have changed, will change, and are relative to culture and society. But beneath scientific knowledge, the studied phenomena are in historical movement. This is what the physical chemist 
Ilya Prigogine pointed to when contributing to the study of entropy: Time is neither static nor symmetric in relation to past and future, as it is treated in some parts of natural sciences, but it has a direction, sometimes called the arrow of time. One never gets the toothpaste back into the toothpaste tube. The irreversibility of time poses serious questions to the established scientific belief in determinism. Phenomena like diffusion, radioactive decay, solar radiation, weather - and not the least organisms and their life - defy any deterministic explanation. Unstable systems can only be understood in terms of probability. "Past and future play different" (Prigogine, 1997).

\subsection{Explanation, understanding - and a third?}

Understanding is not only different from explanation, it is also a condition for explanation. Models of explanation are themselves constructed by means of understanding. Statistical research by questionnaire has as precondition that not only the asking researcher understands the interviewee, but also the respondent understands the questions. This has played an important role for the practice of research in sport participation, in which people are asked: Do you make sports? Or (in Danish): Do you make idrcet? In recent decades, this was differentiated by adding questions like: Do you make motion? And: Do you make physical activity? Depending on these differentiated questions, there were always different outcomes. And these depended on how people understood the questions, and how their understanding changed during historical time (Piilgaard, 2010).

On a meta-level, the understanding of understanding is a relevant problem just for those who work with questionnaires, statistical results, generalization and the demand for representativity. Self-critical sociologists know the paradox very well: People say one thing, mean something other (this is what they understand), and do something third.

Thus, there is not only a difference between the one side and the other side of the research dualisms. There is also connection across. Again: There is no good answer without a good question. And there may be a third way.

The need for thinking a third way is especially revealed when analyzing atmospheres and moods or what in Danish is called stemning and in German Stimmung, voicing. Atmospheres play an important role in movement culture, constituting a sort of energetic dimension of bodily practice side-by-side with the dimensions of space and time (Böhme, 1995; Eichberg, 2010, chap. 8). But it is difficult or even impossible to explain atmospheres. And what makes things still more complex, atmospheres even cannot truly be "understood". Beyond - or more precisely, on this side - of explanation and understanding, there thus seems to be the need for a third way of attention, a precondition to analyze atmospheric relations. To understand, it may be necessary to enter into movement practices and their moods, to experience, undergo and practice them. What is needed is what Michael Polanyi (1966) has called "tacit knowledge".

This leads towards a trialectical relation between question, answer - and "tacit", implicit bodily practice. Or the other way around: there exists a trialectical relation between the body swinging in the rhythm of the drum, factors of explanation, and connections that can be understood. There is a complex relation between implicit knowledge and the different forms of explicit knowledge.

This should, however, not be comprehended as if only a sports active observer was able to analyze sport - as it sometimes has been claimed from the side of conservative insider experts of sport and sport research. That only a footballer can explain football, only a dancer can understand dance, etc. This reduction would be naïve. It would not be at the height of the broader human corporeality, of which every researcher is a part. Should only a human being of medieval times be able to understand the Middle Ages? Should only a Fascist be able to understand Fascism? It is not easy. And yet tacit experience and practice challenge the dialectics between explanation and understanding, as it is has been established in the academic world.

The trialectical relation between explanation, understanding, and implicit knowledge also raises questions concerning the third in the other fields of dualistic constructions discussed above, among these the 
human relation to It, I and You (Buber, 1923/1986) and the trialectics of objectivity, subjectivity, and intersubjectivity. The same is true for the complex relation between the body we have, the body we are, and the inter-bodily relation.

\section{Conclusions and critique: Between theory and philosophy}

What does all this mean for the relation between theory and philosophy? As argued above, theory has a more intense relation to empirical facticity and to the correctness of the answer, while philosophy has a primary relation to questioning basic concepts. Philosophy questions all that seems to be confirmed. And yet, in the practice of research, theory and philosophy may also be connected.

There are philosophies that start by questions - as Martin Heidegger did by his: "What is Being?" but glide into statements and affirmations about the human being and the world. This could even adopt the character of fascist postulates, as Heidegger uttered them in 1933. There are also philosophies that have the ambition to be scientific theory - as Jürgen Habermas' "theory of communicative reason". Philosophy, here, ended up postulating truth.

As an epoch-making (un-) balance between philosophy and theory, Ludwig Wittgenstein's Tractatus logico-philosophicus (1921) deserves particular attention. The Tractatus claimed to be philosophical - and it was, indeed. But it avoided strictly reflecting on the central problem of what the question is. It began with the statement: "1. Die Welt ist alles, was der Fall ist" (World is all that is actual fact). And it ended by the famous postulate: "7. Wovon man nicht sprechen kann, darüber muss man schweigen" (What one cannot talk about, one should keep silence about). All this may be convincing as long as sentences one-sidedly are understood as statements and answers. But this does not fit for questions. If the question is involved, the first sentence could be reformulated as: 1 . World is all, which one can ask about. And the last sentence: 7 . What one cannot talk about, one should ask about (or alternatively: ... one should dance).

Further core sentences of the Tractatus could be - literally - questioned in a similar way. "4.01 Der Satz ist ein Bild der Wirklichkeit" (The sentence is a picture of reality) - or can the sentence also be a question - and thus a picture of potentiality? "4.023 Die Wirklichkeit muss durch den Satz auf ja oder nein fixiert sein" (Reality must by the sentence be fixed to either yes or no) - is there nothing third? "6.5. $Z u$ einer Antwort, die man nicht aussprechen kann, kann man auch die Frage nicht aussprechen. Das Rätsel gibt es nicht. Wenn sich eine Frage überhaupt stellen lässt, so kann sie beantwortet werden " (One cannot ask a question, if one cannot express the answer. The riddle, the mystery does not exist. If one can ask a question, it can also be answered) - does this argument maybe include a problematic censorship of question?

The paradox of the Tractatus was that it was a sort of poem dressed in the terminological style of physics and mathematics, of positivism and functionalism. It was fascinating as a prose poem composing the statements - or rather, the postulates - of New Objectivity (Neue Sachlichkeit) in a crystalline order. The Tractatus became a bible for Neo-Positivism and the Circle of Vienna, teaching a whole generation the message of right and wrong in science. And yet the later Wittgenstein turned critical of his own early work, with good reason. He finally recognized the fundamentally poetical character of scientific knowledge including his own.

Thus, there is no simple either/or. There is internal differentiation in the world of knowledge - but there is also connection between the two sides. As it was said: There is no good answer without a good question. The connection is human life. However, the dialogue is not the way of assimilation, but of challenge. And furthermore: Beyond the dualistic concepts, there is - or can be asked for - a third.

This may be the challenge by which the meeting of sport studies with health science can contribute to qualifying the cultural struggle. This does not happen by adjusting cultural studies to biological-medical models, by transforming culture into factors, and by substituting understanding of connections by explanation of data. But the perspective can be turned the other way round: Sport as a cultural practice of health may question the medical understanding of health. Does it? 


\section{REFERENCES}

Bauman, Bevaegelsesstudier (Movement Studies), Århus: Klim and Gerlev: Bavnebanke, 2002-2010.

Moving Bodies. Oslo: Norwegian School of Sport Sciences, 2002-2008.

Movements. University of Southern Denmark, Institute of Sports Sciences and Clinical Biomechanics $2007 \mathrm{ff}$

University of Southern Denmark Studies in Sport and Movement. Odense: Syddansk Universitetsforlag $2012 \mathrm{ff}$

Andersen, S.S., and Ronglan L.T. (2012) (Eds.). Nordic Elite Sport. Same ambitions - different tracks. Oslo: Universitetsforlaget.

Bachelard, G. (1964). Psychoanalysis of fire. Boston: Beacon. (First French 1938).

Bale, J. (2002). Imagined Olympians: Body Culture and Colonial Representation in Rwanda. Minneapolis: University of Minnesota Press.

Bodenheimer, A. (1984) Warum? Von der Obszönität des Fragens. (Why? About the obscenity of asking. In German) Stuttgart: Reclam.

Böhme, G. (1995). Atmosphäre. Essays zur neuen Ästhetik. (Atmosphere. Essay about the new aesthetics. In German) Frankfurt/Main: Suhrkamp.

Brownell, S. (2008) (Ed.). The 1904 Anthropology Days and Olympic Games: Sport, Race and American Imperialism. Lincoln and London: University of Nebraska Press.

Buber, M. (1986). I and Thou. New York: Collier (First German 1923).

Devereux, G. (1967). From Anxiety to Method in the Behavioral Sciences. The Hague: Mouton.

Eichberg, H. (2005) Racing in the labyrinth? About some inner contradictions of running. In: Athletics, Society \& Identity (pp. 169-192). Athens: Foundation of the Hellenic World.

Eichberg, H. (2010). Bodily Democracy. Towards a Philosophy of Sport for All. London: Routledge.

Eichberg, H. (2012). Das Spiel und die Olympischen Spiele. Zum Unterschied von play und game. (Play and the Olympic Games. On the difference between play and game. In German). DAGS-Mitteilungen. (Transactions of the German Association of Sport Museums, Sport Archives and Sport Collections), 9-14. Garine, I. and Pollock, N. (1995) (Eds.). Social Aspects of Obesity. London: Gordon \& Breach.

Geier, M. (1992). Der Wiener Kreis. (The Circle of Vienna. In German). Reinbek: Rowohlt.

Goodall, J. (1986). The Chimpanzees of Gombe: Patterns of Behavior. Belknap/Harvard University Press.

Héran, François (1988). Comme chiens et chats. Structures et genèse d'un conflit culturel. (Like dogs and cats. Structures and genesis of a cultural conflict. In French). Ethnologie française, 18, 4: 325-337.

Ibsen, B. (2009) (Ed.). Nye stier $i$ den kommunale idratspolitik. (New paths in municipal sports policy. In Danish) Copenhagen: IDAN.

Kreuzer, H. (1969). Literarische und naturwissenschaftliche Intelligenz. Dialog über die „zwei Kulturen”. (Literary and scientific intelligence. Dialogue about the «two cultures ». In German). Stuttgart: Klett.

Kuhn, T.S. (1962). The Structure of Scientific Revolutions. Chicago: University of Chicago Press.

Lüschen, G. (1962). Der Leistungssport in seiner Abhängigkeit vom kulturellen System. (Achievement sport and its dependence of the cultural system. In German). Zentralblatt für Arbeitswissenschaft (Central Journal of Labor Science), 16: 186-190.

McNamee, M. (2008). Sports, Virtues and Vices. Morality Plays. London and New York: Routledge.

Piilgaard, M. (2010). Når sport og motion bliver et spørgsmål om fysisk aktivitet. (When sport and motion become a question of physical activity. In Danish). Forum for idrcet (Forum for Sports), 26, 2: 113-128.

Plessner, H. (1941). Lachen und Weinen. (Laughing and crying. In German). New ed. in Plessner 1982: Gesammelte Schriften. (Collected Works) (pp. 201-387). Frankfurt/Main: Suhrkamp.

Polanyi, M. (1966). The Tacit Dimension. Garden City/New York: Doubleday.

Popper, K. (1960). The Poverty of Historicism. London: Routledge.

Prigogine, I. (1997). End of Certainty. The Free Press.

Seiffert, H. (1969/70). Einführung in die Wissenschaftstheorie. (Introduction to the theory of science. In German). Munich: Beck.

Seppänen, P. (1972). Die Rolle des Leistungssports in den Gesellschaften der Welt. (The role of achievement sport in the societies of the world. In German). Sportwissenschaft, 2: 133-155.

Tang, C. (2010). Yundong: One term for two different body cultures. East Asian Sports Thoughts, Taiwan, 1: 73-103.

Teich, M. et al. (1997). (Eds.). Nature and Society in Historical Context. Cambridge: Cambridge University Press. 
Wittgenstein, L. (1921). Tractatus logico-philosophicus. (Logical-philosophical treatise. In German). $7^{\text {th }}$ ed., Frankfurt/Main: Suhrkamp.

Wright, G.H. von (1971). Explanation and Understanding. Ithaca, New York: Cornell University Press.

AUTHOR'S ADDRESS:

Henning Eichberg

University of Southern Denmark

Institute of Sports Science and Clinical Biomechanics

Campusvej 55

DK-5230 Odense M

Denmark

Email: heichberg@health.sdu.dk 